\title{
Spectral Analysis of Rotor Currents in Frequency- controlled Electric Drives
}

\author{
Vladimir L. Kodkin, Alexandr S. Anikin and Alexandr A. Baldenkov \\ South Ural State University, 76 Lenin prosp, Chelyabinsk, Russia 454080
}

\begin{abstract}
The results of researches of asynchronous electric drives with the frequency control which are carried out for the purpose of establishment of causes and effect relationships between a control method, the implementable standard frequency converter of the Schneider Electric company (ATV-71, ATV-32) and its efficiency are given in article. Tests with asynchronous motors with wound rotor were for the first time carried out. It allowed registering during the experiments the instantaneous values not only the stator currents, but also rotor currents. Authors for the first time applied spectrum analysis of stator and rotor currents, it showed that «sensorless vector» control leads to origin of high-frequency harmonicas with the considerable amplitude and, as a result of they are non-sinusoidal of the created moment and inefficiency of the electric drive. The accelerations that are carried out during the researches to 94, 157 and $251 \mathrm{Rad} / \mathrm{s}$ confirmed this feature of vector control that appears incapable to linearize the asynchronous electric drive as it was supposed authors of a method. These results do not contradict theoretical provisions if not to neglect assumptions which usually become in case of an output of the equations of vector control. Unfortunately, the modern researchers do not subject these assumptions to doubts Continued studies makes it possible to create an effective frequency management of asynchronous electric drives required for current technology.
\end{abstract}

Keywords-squirrel-cage induction motor; slip-ring rotor motor; frequency control; rotor current; spectral analysis; experimental studies; efficiency

\section{INTRODUCTION}

Despite the widespread use of AC electric drives with the frequency control in the industry, theoretical problems remain much. This particularly applies to the implementation of vector control in electric drives with synchronous and asynchronous electric motors.

\section{Problem STATEMENT}

Numerous articles and monographs dedicated to these systems describe methods of their implementation, control algorithms, software etc., but usually give just a vague idea of relevant problems - inaccuracies of the dynamic equations [1], possible mismatch of the equations of model put in control devices, bulkiness of control algorithms, etc. Practically there are no results of experiments showing mismatch and recommendations about overcoming these problems.

Previously conducted pilot studies showed how operation of sensorless vector control is influenced by external loadings of the moment [2]. But even in these studies it was not possible to establish a clearer cause-and-effect relationship between the control algorithms and the operation of the drive. One of the reasons is a limited information about the processes in a squirrel cage motor; usually these are speed signals from the encoder, the amplitude value of the stator current and the coordinates calculated by the frequency converter - electromagnetic moment $\mathrm{M}$, power $\mathrm{P}$, stator current $\mathrm{I}$, etc. As the structure of model on which these variables are calculated is unknown, it is impossible to consider them authentic (except U, I, f). Instantaneous values of the stator current "filled" with a high frequency are not very informative. The experiments on the stand with two asynchronous motors of different types controlled by frequency converters show that the advantages of vector control over scalar are not always so obvious as in guidelines and advertising articles.

\section{MAIN PART}

A new information necessary for understanding the processes in frequency-controlled drives may be obtained using a motor with a slip-ring rotor whose current circuits have been installed in the rotor circuits. Schematic diagram of the drive with the slip-ring induction motor is shown in Figure 1. In addition to the asynchronous motor with a slip-ring rotor (M1), the stand includes the ATV-71 frequency converter from Schneider Electric (UZ1), the speed data were obtained from an encoder (BR) located on the motor shaft. The drive parameters were recorded with a USB oscilloscope (PG) Hantek DSO-2090 and displayed on a personal computer screen.

The stand allowed us to obtain synchronous diagrams of speed and current of the rotor or stator and with the help of software to conduct spectral analysis of these signals.

Before proceeding to the description and analysis of the results of the experiment, let us note once again the possible cause of vector control problems. It is sufficient to consider the basic equations of the mathematical description of an induction motor, which are used to compose vector control algorithms. So, to analyze the operation of an asynchronous motor, most specialists [1, 3, 4] use Park's model of a generalized electric machine [5]. 


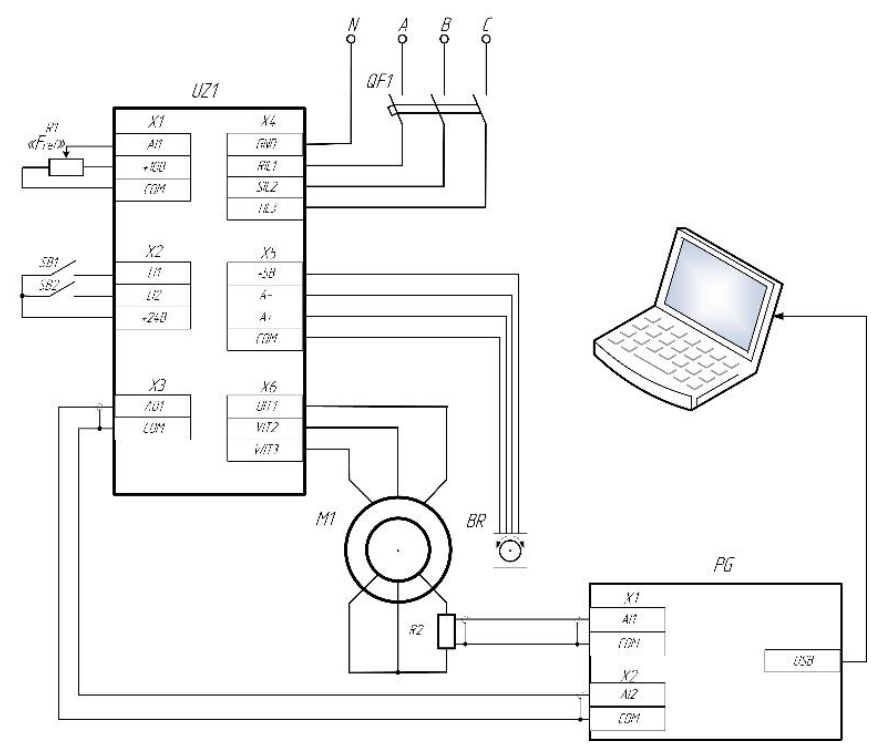

FIGURE I. SCHEMATIC DIAGRAM OF THE DRIVE WITH THE SLIPRING INDUCTION MOTOR

Expression of the electromagnetic moment and angular frequency of rotation in case of a choice of vectors of flux linkage of a rotor and current of the stator (the axis d of the synchronous coordinate system is combined with a vector $\psi_{2}$ ) is as follows [3]:

$$
\mathrm{m}=\frac{3 \cdot \mathrm{z}_{\mathrm{p}} \cdot \mathrm{L}_{\mathrm{m}}}{2 \cdot \mathrm{L}_{2}} \Psi_{2 \mathrm{~d}} \cdot \mathrm{i}_{1 \mathrm{q}}
$$

where $z_{p}-$ is the number of pole pairs of the motor; $\psi_{2 d}-$ is the longitudinal component of the rotor's flux-linkage; $\mathrm{L}_{\mathrm{m}}-$ magnetization inductance; $i_{1 q}-$ is the transverse component of the stator current; $\mathrm{L}_{2}-$ is inductance of the winding of the rotor.

Angular frequency of current of a rotor in case of a choice of vectors of flux linkage of a rotor and current of the stator is as follows:

$$
\omega_{2}=i_{1 q} \frac{L_{m}}{\Psi_{2 d} \cdot T_{2}} .
$$

The longitudinal component of flux linkage of a rotor is defined as follows [3]:

$$
\Psi_{2 \mathrm{~d}}=\mathrm{i}_{1 \mathrm{~d}} \frac{\mathrm{L}_{\mathrm{m}}}{1+\mathrm{T}_{2} \cdot \mathrm{p}},
$$

where $T_{2}=L_{2} / r_{2}$-electromagnetic time constant; $r_{2}$-active resistance of the rotor winding; $p$-Laplace operator.

Projections of the vector of the stator current, taking into account that the axis $\mathrm{d}$ of the synchronous coordinate system is aligned with the vector $\psi_{2}$, i.e. $\psi_{2 q}=0$ [3]:

$$
\mathrm{i}_{1 \mathrm{~d}}=\frac{\Psi_{2 \mathrm{~d}}}{\mathrm{~L}_{\mathrm{m}}}\left(1+\mathrm{T}_{2} \cdot \mathrm{p}\right) ; \mathrm{i}_{1 \mathrm{q}}=\frac{\Psi_{2 \mathrm{~d}}}{\mathrm{~L}_{\mathrm{m}}} \mathrm{T}_{2} \cdot \omega_{2} \text {. }
$$

In equation (1), the electromagnetic moment of the motor is formed as the product of the time functions of the longitudinal component of the magnetic flux $\psi_{2 d}$ and the transverse stator current component $i_{1 d}$. Further, equations (2, 3 and 4) give expressions for Laplace images of the projections of the magnetic flux, current and frequency of the rotor current $\omega_{2}$. The operator image of the electromagnetic moment is formed as the product of the Laplace functions, whereas in strict accordance with the operator calculus it would be necessary to apply the Parseval equality [6]. The error of this "replacement" is insignificant if the dynamics of one of the factors is substantially lower than the dynamics of the other (in deriving the vector control equations under the assumption: $\frac{d \psi_{2}}{d t}=0$ ).

If a change spectrum $\omega_{2}$ is compared to a change spectrum of other signals in these equations - U, I, $\Psi$, etc. the error will be very big since the multiplication of such signals results in considerable signals of higher harmonics that not just brings an error into the electric drive equations, but absolutely "disorganizes" them. I.e. it is impossible to use Laplace transforms, as in the linear differential equations.

It should be noted that in the presence of higher harmonics in current or voltage signals, the formulation of the problem itself is erroneous: to provide a definite position of the current or voltage vectors, since it is impossible to form one channel (slipring voltage or current) simultaneously controlling all harmonics. If in the above equations, connecting the longitudinal and transverse components of currents or currents to substitute the sum of the harmonics of the equation lose their meaning, as well as attempts to control these variables. In this way the vector system controls the fundamental harmonic, and the others are formed "on their own", which leads to large errors and pulsations of the moments, and to the final inefficiency of the drive. In this situation, the scalar control reacting to the instantaneous values of the stator currents is fundamentally more effective, since it controls the total current, regardless of the harmonic component. This experiment is very well confirmed.

Our assumption that the analysis of processes in the rotor of an asynchronous motor will allow us to approach this problem is based on the fact that the processes in the rotor are essentially low-frequency, with respect to the stator processes, therefore they are more informative.

The engine starts up to various speeds - 94, 157, $251 \mathrm{Rad} / \mathrm{s}$, which corresponds to the frequencies of the supply voltage of 30 , 50 and $80 \mathrm{~Hz}$. Figures 2-4 show velocity diagrams (A), stator currents (B) and rotor (C) and their spectra (D, E) with scalar control. 

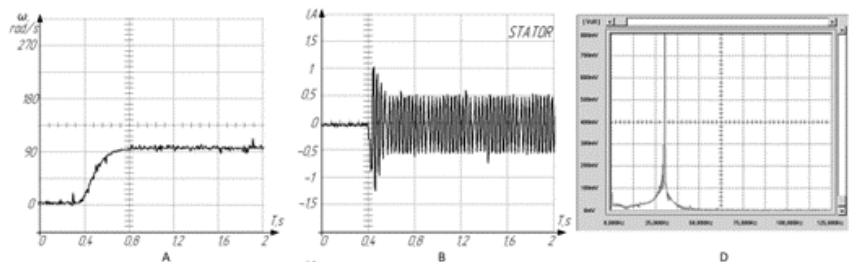

A-Speed

B-Stator curren

C-Rotor current

- Spectral analysis of stator current E - Spectral analysis of rotor current
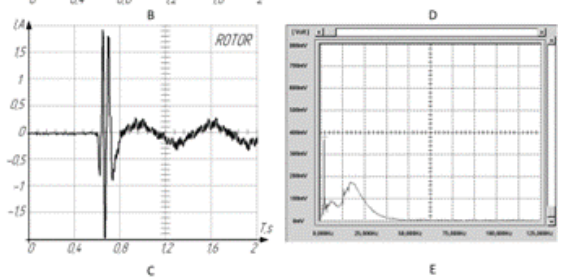

FIGURE II. TRANSIENT OF ALTERNATING CURRENT DRIVE WITH SCALAR CONTROL WITH SLIP-RING INDUCTION MOTOR $(\Omega R E F=94 \mathrm{RAD} / \mathrm{S})$
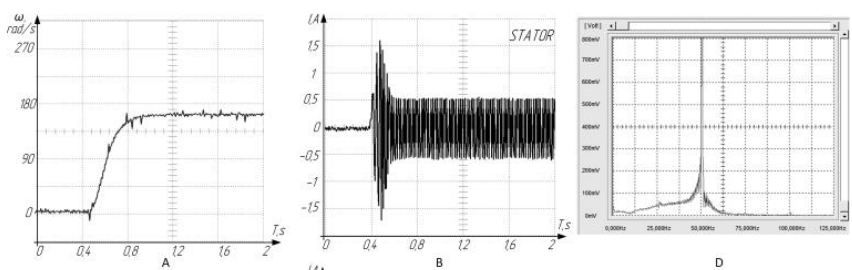

A-Speed

B-Stator current

C-Rotor current

Dpectral analysis of stator current - Spectral analysis of rotor curren
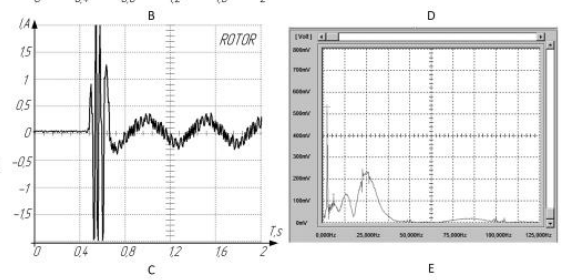

FIGURE III. TRANSIENT OF ALTERNATING CURRENT DRIVE WITH SCALAR CONTROL WITH SLIP-RING INDUCTION MOTOR $(\Omega \mathrm{REF}=157 \mathrm{RAD} / \mathrm{S})$
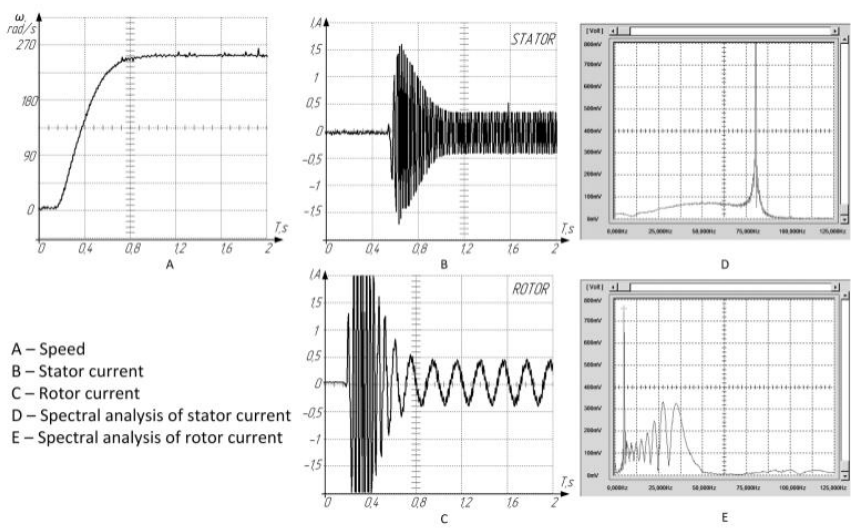

FIGURE IV. TRANSIENT OF ALTERNATING CURRENT DRIVE WITH SCALAR CONTROL WITH SLIP-RING INDUCTION MOTOR $(\Omega \mathrm{REF}=251 \mathrm{RAD} / \mathrm{S})$

Figures 5-7 show similar diagrams, but with vector control.
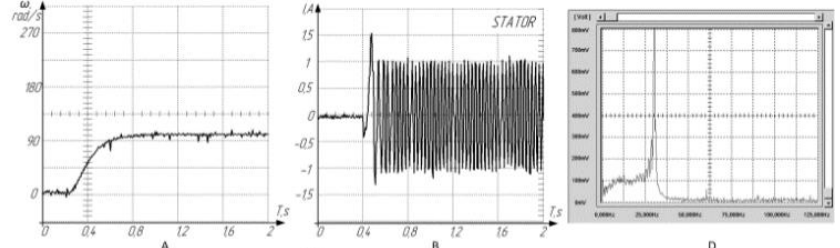

A-Speed

B-Stator current

C-Rotor current

D-Spectral analysis of stator current

$\mathrm{E}-$ Spectral analysis of rotor current

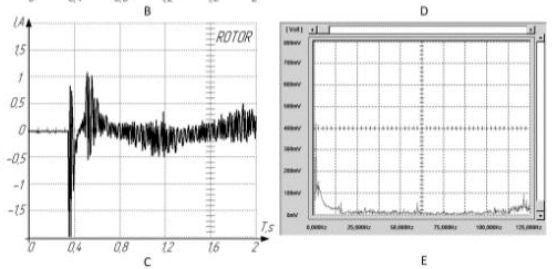

FIGURE V. TRANSIENT OF ALTERNATING CURRENT DRIVE WITH VECTOR CONTROL WITH SLIP-RING INDUCTION MOTOR $(\Omega \mathrm{REF}=94 \mathrm{RAD} / \mathrm{S})$
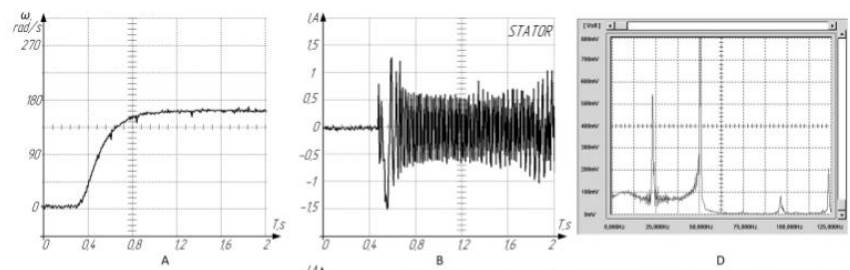

A-Speed

B - Stator current

C-Rotor current

E-Spectral analysis of stator current
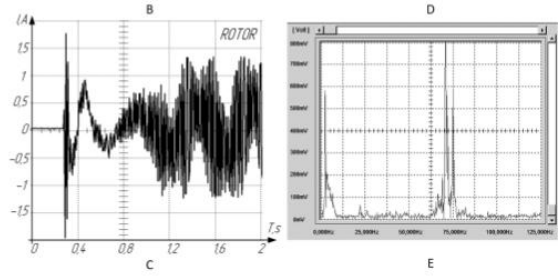

FIGURE VI. TRANSIENT OF ALTERNATING CURRENT DRIVE WITH VECTOR CONTROL WITH SLIP-RING INDUCTION MOTOR $(\Omega \mathrm{REF}=157 \mathrm{RAD} / \mathrm{S})$
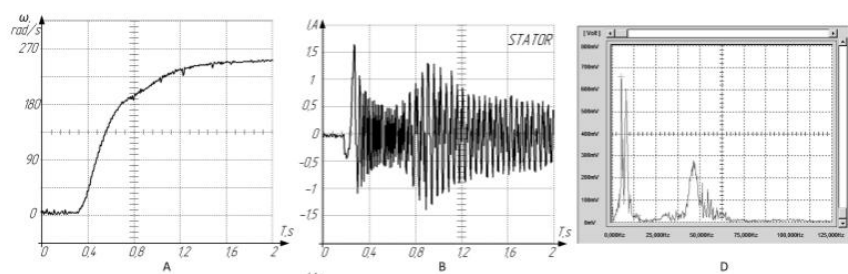

A-Speed

B-Stator curren

C-Rotor current

D-Spectral analysis of stator current E-Spectral analysis of rotor current
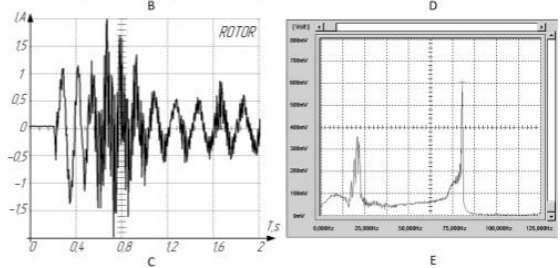

FIGURE VII. TRANSIENT OF ALTERNATING CURRENT DRIVE WITH VECTOR CONTROL WITH SLIP-RING INDUCTION MOTOR $(\Omega \mathrm{REF}=251 \mathrm{RAD} / \mathrm{S})$

The spectrum of stator currents contains the fundamental frequency corresponding to the rotational speed of the motor, especially with scalar control. The spectrum of rotor currents under scalar control lies in the low-frequency range, determined by slip and mechanical processes (Fig. 8). In the spectrum of 
rotor currents, in the vector control, high-frequency components appear that are much higher than the spectrum of mechanical processes (Fig. 9) and form the pulsations of the moment and contribute to the inefficiency of the drive.
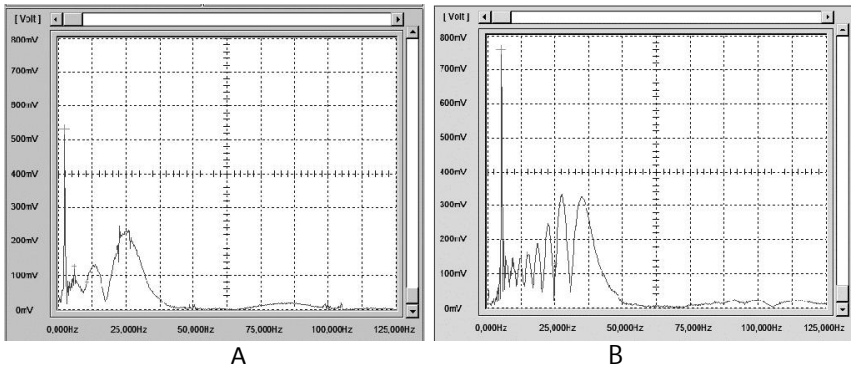

FIGURE VIII. SPECTRAL ANALYSIS OF ROTOR CURRENT SLIP-RING INDUCTION MOTOR WITH SCALAR CONTROL (A - $\Omega R E F=157$ $\mathrm{RAD} / \mathrm{S}, \mathrm{B}-\Omega \mathrm{REF}=251 \mathrm{RAD} / \mathrm{S})$
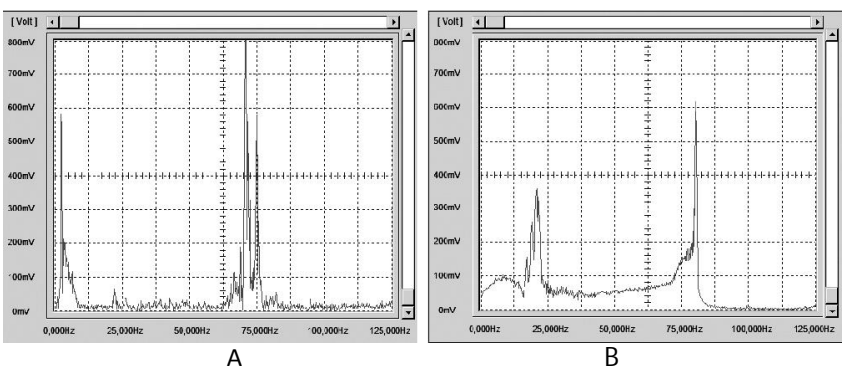

FIGURE IX. SPECTRAL ANALYSIS OF ROTOR CURRENT SLIP-RING INDUCTION MOTOR WITH VECTOR CONTROL $(\mathrm{A}-\Omega$ REF $=157$ $\mathrm{RAD} / \mathrm{S}, \mathrm{B}-\Omega \mathrm{REF}=251 \mathrm{RAD} / \mathrm{S})$

In some cases, these pulsations also appear in the spectrum of stator currents. It follows from these figures that when accelerating to velocities higher than $125 \mathrm{Rad} / \mathrm{s}$ in the rotor current signals, high-frequency harmonics appear in the vector control, which would not appear if the processes were described by equations similar to (1) - (4), I.e. close to linear. It is obvious that the appearance of these high-frequency harmonics in rotor currents is due to their presence in stator currents, which, despite the high carrier frequencies, are barely noticeable, but in some cases (see Figures 6B, 6D, 7B and 7D) and the nature of this manifestation depends on the settings of the drive.

Figure 10-12 shows the velocity diagrams (A), stator currents (B) and their spectrum (C) for the accelerations up to velocities of $94,157,251 \mathrm{Rad} / \mathrm{s}$ with the scalar control of an induction motor with a squirrel cage rotor.
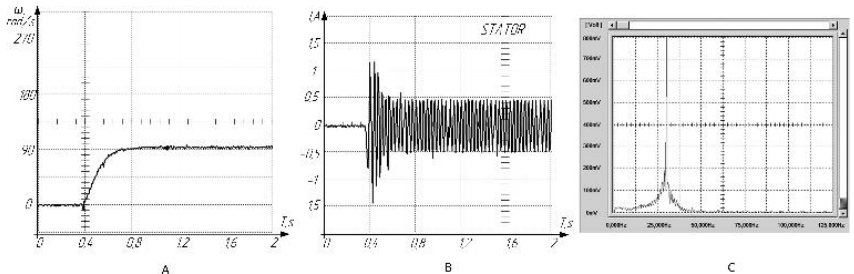

FIGURE X. TRANSIENT OF ALTERNATING CURRENT DRIVE WITH SCALAR CONTROL WITH SQUIRREL-CAGE INDUCTION MOTOR $\quad(\Omega R E F=94 \mathrm{RAD} / \mathrm{S})$
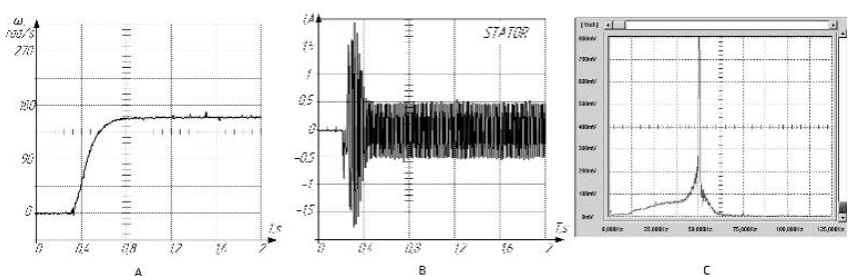

FIGURE XI. TRANSIENT OF ALTERNATING CURRENT DRIVE WITH SCALAR CONTROL WITH SQUIRREL-CAGE INDUCTION MOTOR $\quad(\Omega R E F=157 \mathrm{RAD} / \mathrm{S})$
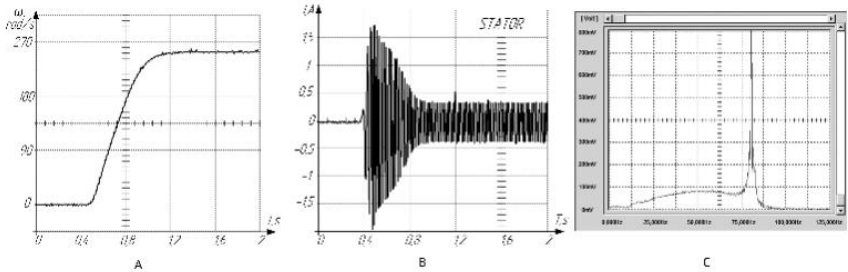

FIGURE XII. TRANSIENT OF ALTERNATING CURRENT DRIVE WITH SCALAR CONTROL WITH SQUIRREL-CAGE INDUCTION MOTOR $\quad(\Omega R E F=251 \mathrm{RAD} / \mathrm{S})$

Figures 13-15 show the speed diagrams (A), stator currents (B) and their spectrum (C) at acceleration to $94,157,251 \mathrm{Rad} / \mathrm{s}$ with vector control of a squirrel-cage motor.
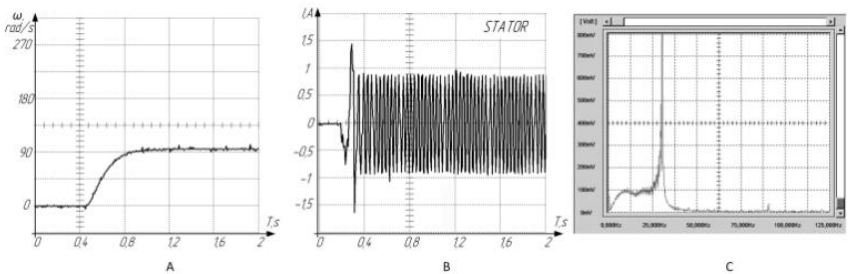

FIGURE XIII. TRANSIENT OF ALTERNATING CURRENT DRIVE WITH VECTOR CONTROL WITH SQUIRREL-CAGE INDUCTION MOTOR $\quad(\Omega R E F=94 \mathrm{RAD} / \mathrm{S})$
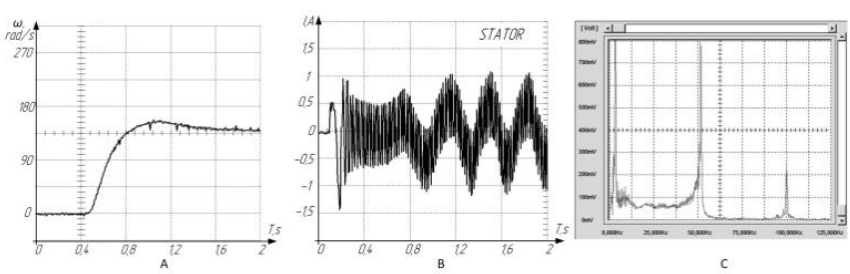

FIGURE XIV. TRANSIENT OF ALTERNATING CURRENT DRIVE WITH VECTOR CONTROL WITH SQUIRREL-CAGE INDUCTION MOTOR $\quad(\Omega R E F=157 \mathrm{RAD} / \mathrm{S})$
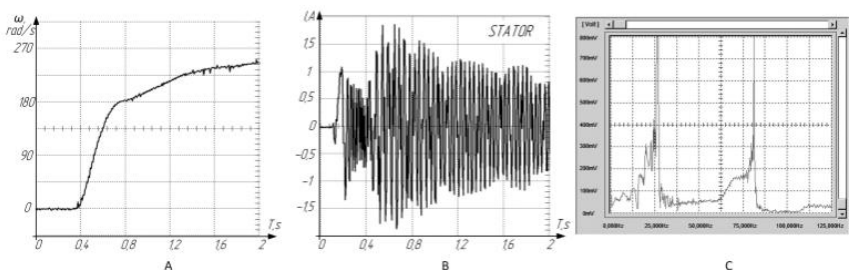

FIGURE XV. TRANSIENT OF ALTERNATING CURRENT DRIVE WITH VECTOR CONTROL WITH SQUIRREL-CAGE INDUCTION MOTOR $\quad(\Omega R E F=251 \mathrm{RAD} / \mathrm{S})$ 
The comparative analysis of diagrams given in Fig. 9-15 with similar diagrams for phase rotor drives had much the same results. This suggested that the processes (stator current and speed diagrams) occurring in squirrel cage motors which are used in most industrial equipment were identical to processes in phase rotor drives used in our study in order to obtain the more detailed information about control processes. This allows us to assume that the features of processes indicated in the paper (inefficiency of vector control) are determined not by the electric motor, but by control algorithms. In addition, it will be possible to state that the developed correction methods, which have proved effective in controlling a motor with a slip-ring rotor, will also be effective in electric drives with squirrel cage induction motors.

\section{CONCLUSION}

Thus, the analysis of these experiments confirms the assumption that the observation of rotor currents makes it possible to accurately establish the mechanism for the occurrence of vector frequency control problems in asynchronous motors. It should also be noted that the proposed method of spectral analysis of processes in currents turns out to be very promising. Further studies of nonlinear processes in drives based on the proposed methods will allow us to analyze the causes of their origin and methods for their compensation.

\section{REFERENCES}

[1] Pozdeev, A.D. Electromagnetic and electromechanical processes in frequency-controlled asynchronous electric drives. - Cheboksary: Publishing house Chuvash University, 1998. - 172 p.

[2] Kodkin V. L., Anikin A. S. Frequency control of asynchronous electric drives in transport //2015 International Siberian Conference on Control and Communications (SIBCON).

[3] Usoltsev, A.A. Vector control of asynchronous motors. Tutorial. - Spb .: ITMO, 2002 - $120 \mathrm{p}$.

[4] Sokolovsky, G.G. AC electric drives with frequency control. - Moscow: "ACADEMIA", 2006 - 267 p.

[5] Park R., Robertson B. The reactances of synchronous machines. // Tr. AIEE, 1928,vol. 47

[6] Vorob'ev, N.N. Theory of series. //4 ed., Revised. And additional. Moscow: Science, 1979, - 408 p. 